\title{
Discovery and Survey of a New Mandarivirus Associated with Leaf Yellow Mottle Disease of Citrus in Pakistan
}

\author{
Jiaxing Wu, ${ }^{1}$ Song Zhang, ${ }^{1}$ Sagheer Atta, ${ }^{2}$ Caixia Yang, ${ }^{3}$ Yan Zhou, ${ }^{1}$ Francesco Di Serio,,${ }^{4,}$ Changyong Zhou, ${ }^{1, \dagger}$ and Mengji Cao ${ }^{1, \dagger}$ \\ ${ }^{1}$ National Citrus Engineering and Technology Research Center, Citrus Research Institute, Southwest University, Beibei, \\ Chongqing 400712, China \\ ${ }^{2}$ Faculty of Agricultural Sciences, Ghazi University, Dera Ghazi Khan 32200, Pakistan \\ ${ }^{3}$ Liaoning Key Laboratory of Urban Integrated Pest Management and Ecological Security, College of Life Science and Engineer- \\ ing Shenyang University, Shenyang 110044, China \\ ${ }^{4}$ Istituto per la Protezione Sostenibile delle Piante, Consiglio Nazionale delle Ricerche, Bari 70126, Italy
}

\begin{abstract}
During biological indexing for viruses in citrus trees, in a collection of Symons sweet orange (SSO) (Citrus sinensis L. Osbeck) graft inoculated with bark tissues of citrus trees from the Punjab Province in Pakistan, several SSO trees exhibited leaf symptoms of vein yellowing and mottle. High-throughput sequencing by Illumina of RNA preparation depleted of ribosomal RNAs from one symptomatic tree, followed by BLAST analyses, allowed identification of a novel virus, tentatively named citrus yellow mottle-associated virus $(\mathrm{CiYMaV})$. Genome features of $\mathrm{CiYMaV}$ are typical of members of the genus Mandarivirus (family Alphaflexiviridae). Virus particles with elongated flexuous shape and size resembling those of mandariviruses were observed by transmission electron microscopy. The proteins encoded by CiYMaV share high sequence identity,

yellow vein clearing virus (CYVCV), the two current members of the genus Mandarivirus. Although CYVCV is the virus most closely related to $\mathrm{CiYMaV}$, the two viruses can be serologically and biologically discriminated from each other. A reverse-transcription PCR method designed to specifically detect $\mathrm{CiYMaV}$ revealed high prevalence $(62 \%)$ of this virus in 120 citrus trees from the Punjab Province, Pakistan, where the novel virus was found mainly in mixed infection with CYVCV and citrus tristeza virus. However, a preliminary survey on samples from 200 citrus trees from the Yunnan Province, China failed to detect $\mathrm{CiYMaV}$ in this region, suggesting that the molecular, serological, and biological data provided here are timely and can help to prevent the spread of this virus in citrus-producing countries.
\end{abstract} conserved motifs, and phylogenetic relationships with the corresponding proteins encoded by Indian citrus ringspot virus (ICRSV) and citrus
Keywords: direct tissue blot immunoassay, HTS, phylogeny
The Citrus genus (family Rutaceae) comprises economically important fruit crops, which are widely cultivated in the world for the production of fresh fruit and juice, as well as other processed goods (Tan and Swain 2007). The yield and quality of these products are affected by many pathogens, including a large number of viruses that infect citrus worldwide (Zhou et al. 2020). However, the causal agents of several virus-like diseases remain to be identified. With more than 2.27 million tons in 2018, Pakistan is the 13th country in terms of citrus production in the world ranking (http://www.fao.org/faostat/en/\#home). Over the years, Citrus spp. cultivated in Pakistan have been affected by two major viruses, citrus tristeza virus (CTV) (Atta et al. 2012; Iftikhar et al. 2009) and citrus yellow vein clearing virus (CYVCV) (Cao et al. 2016; Grimaldi and Catara 1996).

${ }^{\dagger}$ Corresponding authors: M. Cao; caomengji@cric.cn; F. Di Serio; francesco.diserio@ipsp.cnr.it; and C. Zhou; zhoucy@cric.cn

Funding: This research was supported by the National Key R\&D Program of China (2017YFE0110900 and 2019YFD1001800), Fundamental Research Funds for the Central Universities (XDJK2018AA002), Chongqing Research Program of Basic Research and Frontier Technology (cstc2017jcyjBX0016), 111 Project (B18044), and Chongqing Postgraduate Research Innovation Project (CYS19111).

*The $\boldsymbol{e}$-Xtra logo stands for "electronic extra" and indicates that supplementary materials are published online.

The author(s) declare no conflict of interest.

Accepted for publication 17 March 2020.

(C) 2020 The American Phytopathological Society
Genus Mandarivirus (family Alphaflexiviridae) currently includes two species, Indian citrus ringspot virus (ICRSV) as the type species and CYVCV. Mandariviruses have filamentous virions and a positive-sense single-stranded (ss)RNA genome with a $3^{\prime}$ poly (A) tail and six open reading frames (ORFs) encoding replicationassociated polyproteins (REP), triple gene block proteins (TGB1, -2 , and -3 ), the capsid protein (CP), and a nucleic-acid-binding protein (NaBP) (Byadgi et al. 1993; Grimaldi and Catara 1996; Loconsole et al. 2012a; Rustici et al. 2000). ICRSV and CYVCV are transmitted by grafting (Loconsole et al. 2012a; Rustici et al. 2000). Furthermore, CYVCV is also disseminated among citrus and herbaceous plants via the citrus whitefly Dialeurodes citri (Zhang et al. 2019), and the aphids Aphis spiraecola (Zhang et al. 2018) and A. craccivora (Önelge et al. 2011). CYVCV seriously impairs lemon production due to the very severe leaf yellow vein clearing symptoms it induces in the infected plants (Chen et al. 2014; Yu et al. 2017; Zhou et al. 2017).

During a field survey intended to investigate the presence and spread of some of the viruses that impact citrus production in Pakistan, several trees were identified, which tested negative for the targeted viruses but showed virus-like leaf symptoms resembling those induced by CYVCV. In recent years, high-throughput sequencing (HTS) has been frequently used to study virus diversity and to discover novel viruses in many herbaceous and woody plants (Bernardo et al. 2018; Hadidi et al. 2016; Maliogka et al. 2018), including citrus (Cao et al. 2018; Loconsole et al. 2012a,b; Navarro et al. 2018a,b; Vives et al. 2013; Yokomi et al. 2017). Therefore, to investigate whether the symptomatic samples were infected by an unknown virus or virus strains undetectable by the reverse-transcription (RT)PCR methods used in the survey, HTS of citrus transcriptome was performed and a novel virus was identified. Here, the molecular, phylogenetic, biological, ultrastructural, and serological features of a 
hitherto unknown virus, supporting the proposal of classifying it as a novel species in the genus Mandarivirus, are reported. Due to the prevalent leaf symptoms associated with this novel virus, the tentative name citrus yellow mottle-associated virus (CiYMaV) is proposed. An RT-PCR detection method was developed and used here to investigate the prevalence of this novel virus in the Punjab Province of Pakistan, and in the Yunnan Province of China.

\section{Materials and Methods}

Plant materials and bioassays. In total, 120 field samples, mainly showing virus-like symptoms such as leaf yellowing or mottling, were collected in different orchards in the Punjab Province, Pakistan, from 2010 to 2018 . Five bark patches from each tree were separately grafted on a virus-free Symons sweet orange (SSO) (Citrus sinensis L. Osbeck) (Ghorbel et al. 1998). Graft-inoculated plants were grown in an insect-free screenhouse at the Citrus Research Institute, Chongqing, China.

Bioassays of the selected isolate PCV31 were performed by graft and mechanical inoculation of citrus and herbaceous indicators, respectively. Four virus-free seedlings of Chandler pummello (Cp) (C. grandis L. Osbeck), Daidai sour orange (DSO) (C. aurantium L. var. Cyathifera Y. Tanaka), Dweet tangor (DT) (C. reticulata L. $\times C$. sinensis L.), Eureka lemon (EL) (C. limon L. Burm. f.), Mexican lime (ML) (C. aurantifolia Christ. Swingle), Morocco sour orange (MSO) (C. aurantium L.), Rough lemon (RL) (C. jambhiri Lush.), Tarocco blood orange (TBO) (C. sinensis L. Osbeck), and Washington navel orange (WNO) (C. sinensis L. Osbeck) and SSO were graft inoculated with bark from the isolate PCV31. Three indicator seedlings of each species were also grafted with bark patches from virus-free SSO and used as negative control replicates. For mechanical inoculations, leaves (about $1 \mathrm{~g}$ ) of isolate PCV31 SSO were homogenized in a $0.02-\mathrm{M}$ phosphate solution containing $0.1 \%$ sodium nitrite to inoculate, by mechanical abration with carborundum dust, the leaves of herbaceous plants (20 plants/species); namely Chenopodium quinoa, C. amaranticolor, Cucumis sativus, Nicotiana benthamiana, Phaseolus vulgaris, Vicia faba, and Vigna unguiculata. All of the inoculated plants were maintained in an incubator at 25 $\pm 1^{\circ} \mathrm{C}, 60$ to $70 \%$ relative humidity, and a photoperiod of $16 \mathrm{~h}$ of light and $8 \mathrm{~h}$ of darkness. Detection of CiYMaV in young leaves was conducted by RT-PCR (see below) at 1, 3, and 5 months postinoculation (mpi), and twice for the herbaceous hosts (15 days and 28 days postinoculation). All grafted plants were also assayed for viroid infection 1 year postinoculation (ypi).

Virus, viroid, and 'Candidatus Liberibacter asiaticus' testing. Total RNA was extracted by the EASY spin Plus Complex Plant RNA Kit (Aidlab Biotech, Beijing, China), using 100 to $150 \mathrm{mg}$ of leaf tissue from each sample. Virus and viroid-specific detection primers for citrus concave gum-associated virus $(\mathrm{CCGaV})$, citrus leaf blotch virus (CLBV), citrus psorosis virus (CPsV), citrus tatter leaf virus (CTLV), CTV, CYVCV, citrus virus A (CiVA), satsuma dwarf virus (SDV), citrus bark cracking viroid (CBCVd), citrus bent leaf viroid (CBLVd), citrus dwarfing viroid $(\mathrm{CDVd})$, citrus viroid $\mathrm{V}(\mathrm{CVd}-\mathrm{V})$, and hop stunt viroid (HSVd) were used as previously reported (Cao et al. 2009, 2013, 2017; Chen et al. 2015; Gao et al. 2006; Lv et al. 2007; Song et al. 2011; Navarro et al. 2018a,b; Zhou et al. 2004) (Supplementary Table S1). RT-PCR was carried out using the PrimeScript One-Step RT-PCR Kit ver. 2 and following the standard provided protocol (Takara, Osaka, Japan). Potential infection by 'Candidatus Liberibacter asiaticus' was tested by PCR using DNA preparation obtained by a Biospin Omni Plant Genomic DNA Extraction Kit (BioFlux, Tokyo, Japan), specific primers designed by Jagoueix et al. (1996), and the $2 \times$ Taq PCR Master Mix (Promega Corp., Madison, WI, U.S.A.) following the standard protocol. The program set for PCR was $3 \mathrm{~min}$ at $95^{\circ} \mathrm{C}$ for denaturation; followed by 35 cycles of $95^{\circ} \mathrm{C}$ for $30 \mathrm{~s}$ (denaturation), $35 \mathrm{~s}$ at $64^{\circ} \mathrm{C}$ (annealing), and $80 \mathrm{~s}$ at $72^{\circ} \mathrm{C}$ (elongation); and then a final extension for $7 \mathrm{~min}$ at $72^{\circ} \mathrm{C}$.

HTS and virus discovery. Total RNA was extracted as reported above and a ribosomal RNA-depleted cDNA library was constructed with a TruSeq RNA Sample Prep kit (Illumina, San Diego, CA, U.S.A.). After ascertaining the quality of the samples by Qubit 2.0 and Agilent 2100, the library was sequenced using an Illumina HiSeq $\mathrm{X}$-ten platform (MegaGenomics, Beijing, China) to generate 150-bp paired-ended reads. Filtering low-quality reads and trimming adaptor sequences of output raw reads through the CLC Genomics Workbench 9.5 (Qiagen, Boston, MA, U.S.A.) produced clean reads, which were then mapped to the citrus reference genomes (Wu et al. 2014; Xu et al. 2013) to remove host reads. The remaining nonhost reads were then subjected to a de novo assembly using the Trinity program to merge the short sequence reads into longer contigs and annotated based on sequence homology by BLASTn and BLASTx searches in NCBI databases (Cao et al. 2019).

Virus genome determination. The full genome of the novel virus CiYMaV was sequenced by amplifying overlapping cDNAs generated by RT-PCR performed using primers designed based on the CiYMaV contig (Supplementary Table S1). The $5^{\prime}$ and $3^{\prime}$ terminal sequences were amplified by the rapid amplification of cDNA ends (RACE) technique with the gene-specific primers (Supplementary Table S1) according to the manufacturer's protocol (Invitrogen, Carlsbad, CA, U.S.A.). The PCR products of expected sizes were purified using a Gel Extraction Kit (Omega Bio-Tek, Norcross, GA, U.S.A.), and cloned into a pEASY-T1 Vector System (TransGen, Beijing, China). At least five clones of each amplicon were analyzed by gel electrophoresis and sequenced fully and the complete genome sequence was assembled using the SeqMan software from the Lasergene sequence analysis package (DNAStar, Madison, WI, U.S.A.).

Sequence and phylogenetic analysis. The full virus genome sequence was uploaded to the ORF finder (https://www.ncbi.nlm.nih.gov/orffinder/) to search for potential ORFs in the genomic or antigenomic sense, and the corresponding translated protein sequences were analyzed by the Conserved Domain Database (http:// www.ncbi.nlm.nih.gov/Structure/cdd/wrpsb.cgi/) for identifying conserved domains. Pairwise sequence comparison was performed using the CLC Genomics Workbench 9.5. Results of phylogenetic analyses were presented as cladograms generated by the MEGA7.0 (neighbor-joining method), using bootstrap replicate 1000, with the values less than $45 \%$ not shown.

Transmission electron microscopy observations. Crude extracts from the symptomatic SSO inoculated with the isolate PCV31 and from a healthy tree were individually prepared and analyzed by transmission electron microscopy (TEM). Fresh leaf pieces were homog-

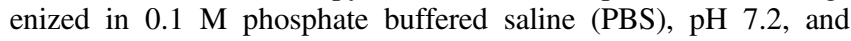
centrifuged at $9,056 \times g$ for $8 \mathrm{~min}$. The supernatant was negatively stained in $2 \%$ (wt/vol) phosphotungstic acid ( $\mathrm{pH} 6.7 ; 10 \mathrm{~s})$, and examined by TEM (Hitachi TEM System, Tokyo, Japan). Likewise, leaf extracts from inoculated herbaceous hosts were also examined by TEM for the presence of virus particles.

Direct tissue blot immunoassay. A direct tissue blot immunoassay (DTBIA) technique, previously described by Bin et al. (2015), was applied in this study. Briefly, nitrocellulose filter membranes (Bio-Rad Laboratories, Hercules, CA, U.S.A.) were cut to a suitable size and a pencil was used to draw a grid and mark each unit for an individual sample test. The stem or petiole of the sample was cut through with a razor, and the resulting cross section was pressed evenly on the membrane. Each sample was imprinted four to six times using different petioles and replacing the razor for each sample. Subsequently, the membrane was placed in $1 \%$ bovine serum albumin in PBS solution for $1 \mathrm{~h}$ at room temperature on a shaker at $100 \mathrm{rpm}$. The membrane was then incubated for $1.5 \mathrm{~h}$ in 1:8,000 diluted CYVCV-specific monoclonal antibodies (MAbs) $1 \mathrm{E} 1 \quad(9.48 \mathrm{mg} / \mathrm{ml})$ or $26 \mathrm{~A} 1$ $(8.87 \mathrm{mg} / \mathrm{ml})$ produced at the Zhejiang University, Hangzhou, China (Liu et al. 2016). After washing the membrane three times in a PBS solution containing $0.5 \%$ Tween 20 , it was then immersed for $1.5 \mathrm{~h}$ in a solution of 1:2,000 diluted alkaline phosphatase-conjugated goat antimouse immunoglobulin G (Bin et al. 2015). Finally, the membrane was developed by addition of nitro blue tetrazolium chloride/5bromo-4-chloro-3-indolyl phosphate as instructed (Promega Corp.) to detect positive charcoal-gray signals.

Virus detection and study of sequence variation in the CP gene. To investigate the occurrence of CiYMaV in citrus orchards, virus-specific detection primers (JC-CiYMaV-F/R) were 
designed targeting the gene coding for the CiYMaV CP (Supplementary Table S1) and applied using the PrimeScript One-Step RT-PCR Kit ver. 2 (Takara). The following RT-PCR protocol was used. RNA templates extracted as described above plus RNase-free distilled $\mathrm{H}_{2} \mathrm{O}(1+1 \mu \mathrm{l})$ were first predenatured for $5 \mathrm{~min}$ at $95^{\circ} \mathrm{C}$; then combined with the PCR mix $(13 \mu \mathrm{l})$ on ice, incubated for $30 \mathrm{~min}$ at $50^{\circ} \mathrm{C}$ for the initial RT, and denatured for $5 \mathrm{~min}$ at $95^{\circ} \mathrm{C}$; then subjected to 35 cycles of $30 \mathrm{~s}$ of denaturation, $30 \mathrm{~s}$ of annealing at $55^{\circ} \mathrm{C}$, and $40 \mathrm{~s}$ of elongation $(1 \mathrm{~kb} / \mathrm{min})$ at $72{ }^{\circ} \mathrm{C}$; with a final 7 -min elongation at $72^{\circ} \mathrm{C}$. In addition, the full $\mathrm{CP}$ gene (987 nucleotides [nt]) was amplified using the specific primer pair (CiYMaV-CP-F/R) to study its sequence diversity. For this purpose, the same RT-PCR system and protocol were used, with the modifications of extending the 40-s elongation step to $1 \mathrm{~min}$ and the final elongation to $10 \mathrm{~min}$.

\section{Results}

Preliminary survey of citrus viruses. In total, 120 citrus samples were collected from different orchards of the Punjab Province, Pakistan, and used to graft inoculate virus-free SSO seedlings. Many of the inoculated SSO plants displayed leaf symptoms of chlorosis (yellowing, mosaic, mottling, and vein clearing) (Fig. 1). Leaf samples from all of the grafted trees were collected and tested by RT-PCR using primers designed to specifically detect six widely distributed citrus viruses, including CLBV, CPsV, CTLV, CTV, CYVCV, and SDV (Supplementary Table S1). Two novel viruses, CCGaV and CiVA, were recently reported in citrus, with at least $\mathrm{CCGaV}$ found associated with leaf symptoms (Navarro et al. 2018a,b). Therefore, the presence of these two latter viruses was also checked by RTPCR with cognate primers (Supplementary Table S1). Only CTV and CYVCV were detected in the tested trees, with incidence rates of 45 and $82.5 \%$, respectively (Table 1). In $35.8 \%$ of the tested plants, both viruses were present. Ten samples tested negative for all of the targeted viruses, with six of them (isolates PCV31, PCV49, PCV59, PCV62, PCV64, and PCV82) corresponding to SSO trees displaying leaf symptoms of vein yellowing accompanied by mottling at a later stage (Fig. 1). These samples were further analyzed by specific PCR assay to detect potential infection by ' $\mathrm{Ca}$. L. asiaticus', which could also induce leaf yellowing in citrus indicators; however, given the negative results, the possible involvement of this pathogen in the observed symptomatology was also excluded. To further investigate whether these samples were infected by viruses not detected by the methods used in the survey, one of these samples (PCV31) was further tested using the HTS technique.

Identification of a new virus by HTS and BLAST analysis. Sequencing of the library built from PCV31 resulted in a dataset
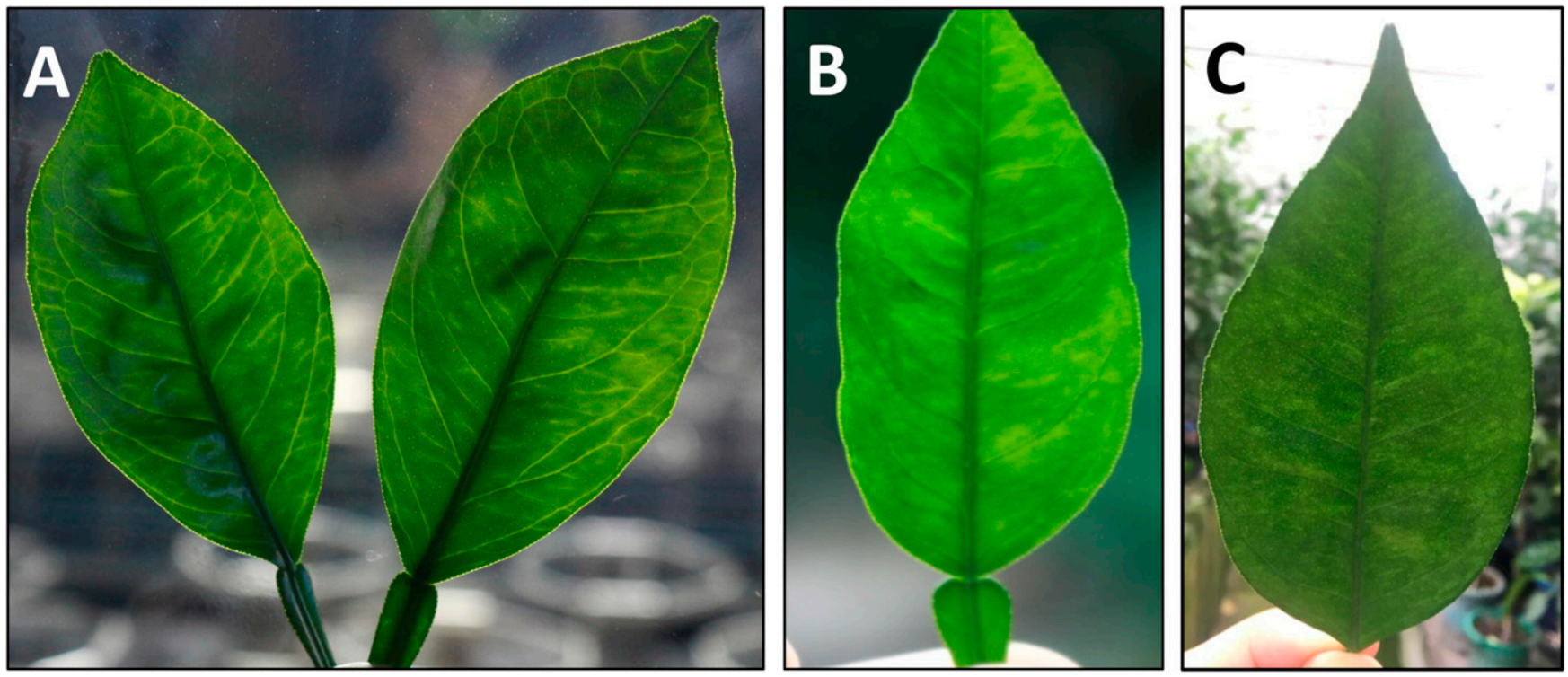

Fig. 1. Symptoms observed on leaves of Symons sweet orange (SSO) (Citrus sinensis L. Osbeck) indicator plants graft inoculated with bark from field isolates from Pakistan and that, according to results of specific reverse-transcription PCR assays, were not infected by citrus concave gum-associated virus, citrus psorosis virus, citrus tatter leaf virus, citrus tristeza virus, citrus yellow vein clearing virus, citrus virus A, satsuma dwarf virus, or 'Candidatus Liberibacter asiaticus'. A, Vein yellowing symptom appeared in a first stage (3 months postinoculation); $\mathbf{B}$ and $\mathbf{C}$, mottling symptom appeared 2 to 3 weeks later.

Table 1. Detection by reverse-transcription (RT)-PCR of citrus tristeza virus (CTV), citrus yellow vein clearing virus (CYVCV), citrus yellow mottleassociated virus (CiYMaV), citrus concave gum-associated virus $(\mathrm{CCGaV})$, citrus leaf blotch virus (CLBV), citrus tatter leaf virus (CTLV), citrus psorosis virus (CPsV), citrus virus A (CiVA), and satsuma dwarf virus (SDV) in 120 citrus samples from Pakistan from 2010 to 2018

\begin{tabular}{lcc}
\hline Virus & Positive samples $^{\mathbf{a}}$ & Positive ratio (\%) $^{\mathbf{b}}$ \\
\hline CTV & 0 & 0 \\
CYVCV & 2 & 1.7 \\
CiYMaV & 6 & 5 \\
CTV + CYVCV & 40 & 33.3 \\
CTV + CiYMaV & 11 & 9.2 \\
CiYMaV + CYVCV & 54 & 45 \\
CTV + CYVCV + CiYMaV & 3 & 2.5 \\
\hline
\end{tabular}

${ }^{a}$ RT-PCR failed to detect any CTV, CYVCV, or CiYMaV in 4 of 120 samples.

b CCGaV, CLBV, CTLV, CPsV, CiVA, and SDV were not detected in 120 samples. containing $83,931,384$ raw reads. Data processing designed to eliminate the host-derived sequences retained the $3.34 \%$ candidate nonhost clean reads for de novo assembly. Analyses of assembled reads by BLAST identified a single contig of 7,462 nt, with the closest nucleotide sequence identity with CYVCV (accession number KT606513; 74.3\%, e-value $=0$ ) and ICRSV (accession number AF406744; $72.16 \%$, e-value $=0$ ). These data suggested the possible presence of a mandarivirus in PCV31 which was further confirmed by RT-PCR using the primer pair JC-CiYMaV-F/R (Supplementary Table S1) and new RNA preparations from the PCV31 isolate (data not shown). The full genome sequence of the putative virus (accession number MK957246) was determined and confirmed by cloning and sequencing overlapping cDNA fragments generated by RT-PCR and RACE. This virus was provisionally named $\mathrm{CiYMaV}$ due to the leaf symptoms observed in the inoculated SSO plants (Fig. 1). Contigs sharing high sequence identity with viroids CBLVd, HSVd, CDVd, CBCVd, and CVd-V were also identified in the same library. 
Sequence analyses. CiYMaV showed the highest genome sequence identity (72.43\%) to the CYVCV-YN isolate (accession number KP313242) (Table 2). The genome of CiYMaV contained six ORFs on the positive strand that were flanked by a $5^{\prime}$ untranslated region (UTR) of $77 \mathrm{nt}$ and a 36-nt 3' UTR followed by a poly (A) tail (Fig. 2A), resembling the UTRs previously reported in the genome of mandariviruses. Interestingly, whereas the $3^{\prime}$ UTR is almost identical (97 to $100 \%$ ) to that of other mandariviruses, the $5^{\prime}$ UTR showed a much lower identity (76 to $82 \%$ ) with the corresponding region of members of the genus Mandarivirus.

The CiYMaV ORF1 (nucleotides 78 to 4,973 ) encodes a 1,631amino-acid (aa) putative replicase (REP, $184.2 \mathrm{kDa}$ ) protein with four domains typical of REPs of members of the genus Mandarivirus (Loconsole et al. 2012a; Prabha and Baranwal 2012): methyltransferase (Met, pfam01660, amino acids 39 to 328) (Ferron et al. 2002), AlkB oxygenase (pfam13532, amino acids 573 to 661) (Bratlie and Drabløs 2005), helicase 1 (Hel-1, pfam01443, amino acids 909 to 1,139 ) (Skryabin et al. 1988), and RNA-dependent RNA polymerase 2 (RdRp-2, pfam00978, amino acids 1,306 to 1,505) (Koonin 1991). This protein shared the maximum amino acid sequence identity with members of genus Mandarivirus (80 to 82\%) (Table 2).
A TGB comprising the overlapping ORF2 (nucleotides 4,981 to 5,658 ), ORF3 (nucleotides 5,636 to 5,965), and ORF4 (nucleotides 5,892 to 6,074 ) is seemingly responsible for the expression of three synergic proteins (TGB1 to -3) that may contribute to virus cell-tocell and systemic movement in the plant (Adams et al. 2004, 2009; Chou et al. 2013; Mushegian and Koonin 1993), as previously reported for other plant viruses such as fovea-, carla-, and potexviruses (Jelkmann 1994; Rupasov et al. 1989; Ur Rehman et al. 2019; Zhang et al. 1998). TGB1 (255 aa) is a putative protein of $25.02 \mathrm{kDa}$, with a Hel-1 domain (pfam01443, amino acids 24 to 217) (Morozov and Solovyev 2003). TGB2 (109 aa), a 12.4-kDa putative protein with the conserved domain Plant_vir_prot (pfam01307, aa 38 to 60), was found to be related to the movement proteins of potex-, hordei-, and carlaviruses. TGB3 (60 aa) is the smallest protein $(6.4 \mathrm{kDa})$ of the three and contains a 7-kDa viral CP-like domain (pfam029495) at amino acids 22 to 58 . Although TGB1 and TGB2 showed the greatest amino acid sequence identity (63.72 and $68.47 \%$, respectively) with CYVCV isolates, TGB3 shared the highest identity (78.69\%) with ICRSV-K1 isolates (Table 2).

ORF5 (nucleotides 6,098 to 7,075) encodes a putative $35.8-\mathrm{kDa}$ (325-aa) protein that contains the pfam00286 domain (amino acids

Table 2. Pairwise nucleotide (nt) and amino acid (aa) sequence identity between citrus yellow mottle-associated virus (CiYMaV) and sequence variants of citrus yellow vein clearing virus (CYVCV) and Indian citrus ringspot virus (ICRSV) belonging to the genus Mandarivirus

\begin{tabular}{|c|c|c|c|c|c|c|c|c|c|c|c|c|c|c|c|}
\hline \multirow[b]{3}{*}{ Isolate $^{\mathbf{a}}$} & \multicolumn{15}{|c|}{ Identity $(\%)^{\mathbf{b}}$} \\
\hline & \multirow{2}{*}{$\frac{\text { Genome }}{\text { nt }}$} & \multirow{2}{*}{$\frac{5^{\prime} \text { UTR }}{n t}$} & \multicolumn{2}{|c|}{ ORF1 (REP) } & \multicolumn{2}{|c|}{ ORF2 (TGB1) } & \multicolumn{2}{|c|}{ ORF3 (TGB2) } & \multicolumn{2}{|c|}{ ORF4 (TGB3) } & \multicolumn{2}{|c|}{ ORF5 (CP) } & \multicolumn{2}{|c|}{ ORF6 (25K) } & \multirow{2}{*}{$\frac{3^{\prime} \text { UTR }}{\text { nt }}$} \\
\hline & & & nt & aa & nt & aa & nt & aa & nt & aa & nt & aa & nt & aa & \\
\hline CYVCV-Y1 & 72.08 & 82.05 & 72.89 & 82.07 & 64.01 & 63.72 & 71.21 & 67.57 & 71.58 & 72.13 & 70.59 & 75.15 & 76.83 & 70.40 & 100 \\
\hline CYVCV-PK (KP313241) & 72.30 & 82.05 & 73.31 & 82.67 & 64.16 & 63.72 & 70.61 & 68.47 & 70.49 & 70.49 & 70.39 & 74.55 & 76.98 & 70.85 & 100 \\
\hline CYVCV-YN (KP313242) & 72.43 & 82.05 & 73.31 & 82.73 & 64.16 & 63.72 & 70.91 & 68.47 & 69.40 & 68.85 & 71.40 & 75.15 & 76.98 & 71.30 & 100 \\
\hline ICRSV-K1 (NC_003093) & 70.12 & 76.92 & 70.54 & 80.89 & 61.06 & 61.95 & 65.76 & 65.77 & 73.22 & 78.69 & 72.90 & 74.85 & 80.87 & 78.48 & 97.22 \\
\hline ICRSV-Pu (HQ324250) & 69.86 & 78.21 & 70.32 & 80.35 & 60.91 & 62.83 & 66.67 & 67.57 & 71.58 & 78.69 & 72.20 & 73.64 & 80.72 & 76.23 & 97.22 \\
\hline
\end{tabular}

a Isolate (accession number).

${ }^{\mathrm{b}} \mathrm{UTR}=$ untranslated region, $\mathrm{ORF}=$ open reading frame, $\mathrm{REP}=$ replication-associated polyproteins, $\mathrm{TGB}=$ triple gene block, $\mathrm{CP}=$ capsid protein, and $25 \mathrm{~K}=$ encoded putative protein of $25 \mathrm{kDa}$.
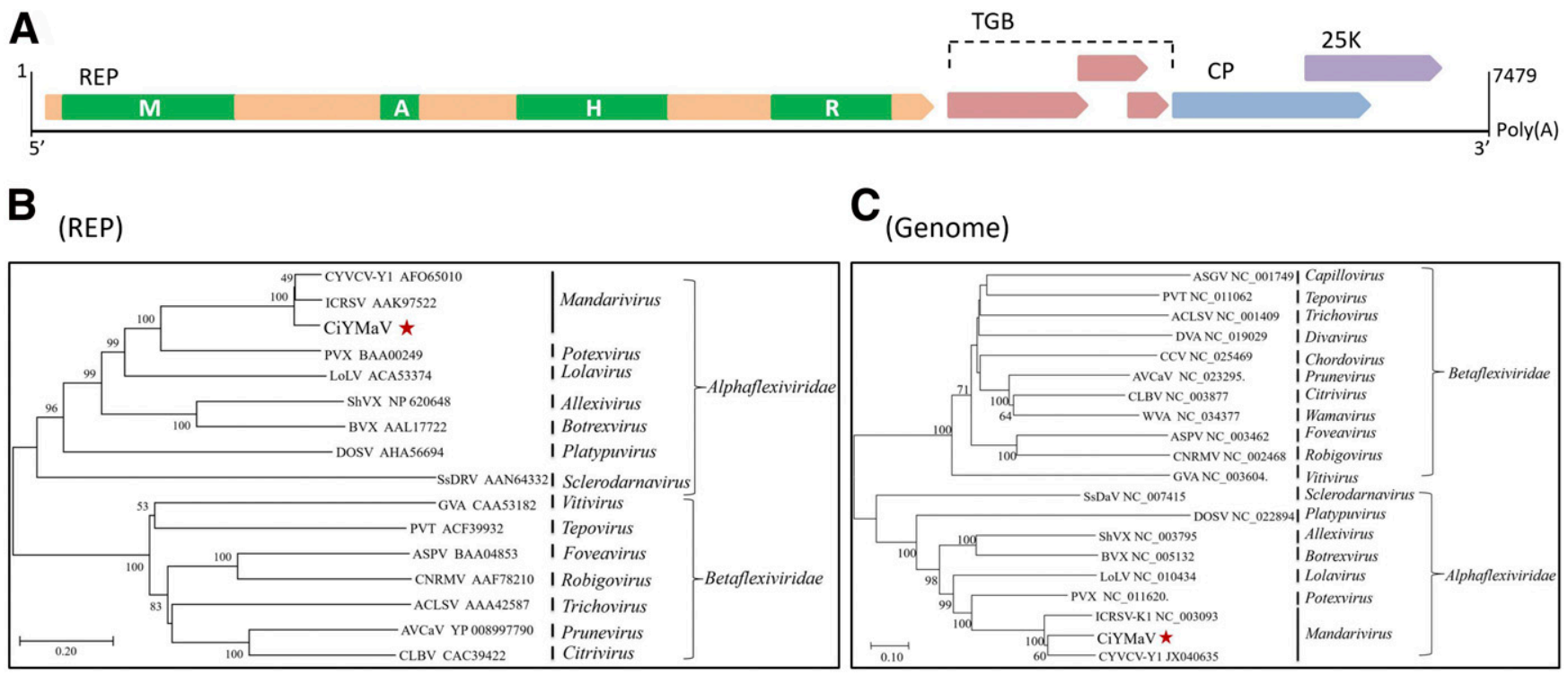

Fig. 2. Genome structure of citrus yellow mottle-associated virus (CiYMaV) and phylogenetic analyses. A, Schematic representation of the genome architecture of CiYMaV. Open reading frames and conserved domains were identified using conserved domain database search at NCBI. REP = replication-associated polyproteins, $M=$ viral methyltransferase domain, $\mathrm{A}=$ AlkB-like domain, $\mathrm{H}=$ viral helicase domain, $\mathrm{R}=\mathrm{RNA}$-dependent $\mathrm{RNA}$ polymerase 2 domain, $\mathrm{TGB}=$ triple gene block, $\mathrm{CP}=$ capsid protein, and $25 \mathrm{~K}=$ encoded putative protein of $25 \mathrm{kDa}$. Phylogenetic analyses of $\mathbf{B}$, amino acid sequences of the REP gene encoded by CiYMaV and $\mathbf{C}$, the whole genome nucleotide of CiYMaV and the REP and genome of representative members of the families Alphaflexiviridae and Betaflexiviridae. Viruses included in the analyses are citrus yellow vein clearing virus (CYVCV), Indian citrus ringspot virus (ICRSV), shallot virus X (ShVX), Botrytis virus X (BVX), Lolium latent virus (LoLV), donkey orchid symptomless virus (DOSV), potato virus X (PVX), Sclerotinia sclerotiorum debilitation-associated RNA virus (SSDRV), apple stem pitting virus (ASPV), cherry necrotic rusty mottle virus (CNRMV), citrus leaf blotch virus (CLBV), apricot vein clearing associated virus (AVCaV), potato virus T (PVT), apple chlorotic leaf spot virus (ACLSV), grapevine virus A (GVA), watermelon virus A (WVA), and carrot Ch virus 1 (CCV1). Phylogenetic trees were inferred by the neighbor-joining method using 1,000 bootstrap replicate, with the values less than $45 \%$ not shown. 
140 to 278) of potex- and carlavirus CPs. This protein shared the highest amino acid sequence identity $(75 \%)$ with the $\mathrm{CP}$ encoded by CYVCV (Table 2 ).

ORF6 (nucleotides 6,775 to 7,443) partially overlaps with ORF5 and encodes a hypothetical $\mathrm{NaBP}$ (222 aa and 25.4 KDa). The amino acid sequence identity between this protein and corresponding proteins from mandariviruses was within the range of 70 to $78 \%$ (Table 2).

Phylogenetic analyses. Phylogenetic trees reconstructed with the sequences of REPs encoded by representative members of the families Alphaflexiviridae and Betaflexiviridae and CiYMaV showed that this virus and the two mandariviruses CYVCV and ICRSV clustered into a single clade, supported by high bootstrap values (Fig. 2B). Similarly, the three viruses clustered in the same clade in a phylogenetic tree generated using the full genome sequences of representative members of the Alphaflexiviridae and Betaflexiviridae families (Fig. 2C), thus supporting close phylogenetic relationships between $\mathrm{CiYMaV}$ and the other members of the genus Mandarivirus.

Serological test. Taking advantage of the availability of two MAbs against CYVCV (MAbs 26A1 and 1E1), possible serological relationship between $\mathrm{CiYMaV}$ and $\mathrm{CYVCV}$ was further investigated. Leaves of tender shoots from trees of different Citrus spp. infected by CiYMaV (and not by CYVCV), were tested by DTBIA using separately the 26A1 and 1E1 antibodies specific to the CP of CYVCV. Samples from a tree infected by CYVCV (and not by $\mathrm{CiYMaV}$ ) were used as positive controls. The absence of mixed infections (CiYMaV plus CYVCV) in these sample was confirmed by RT-PCR (Fig. 3A). Although samples infected by CiYMaV did not

A
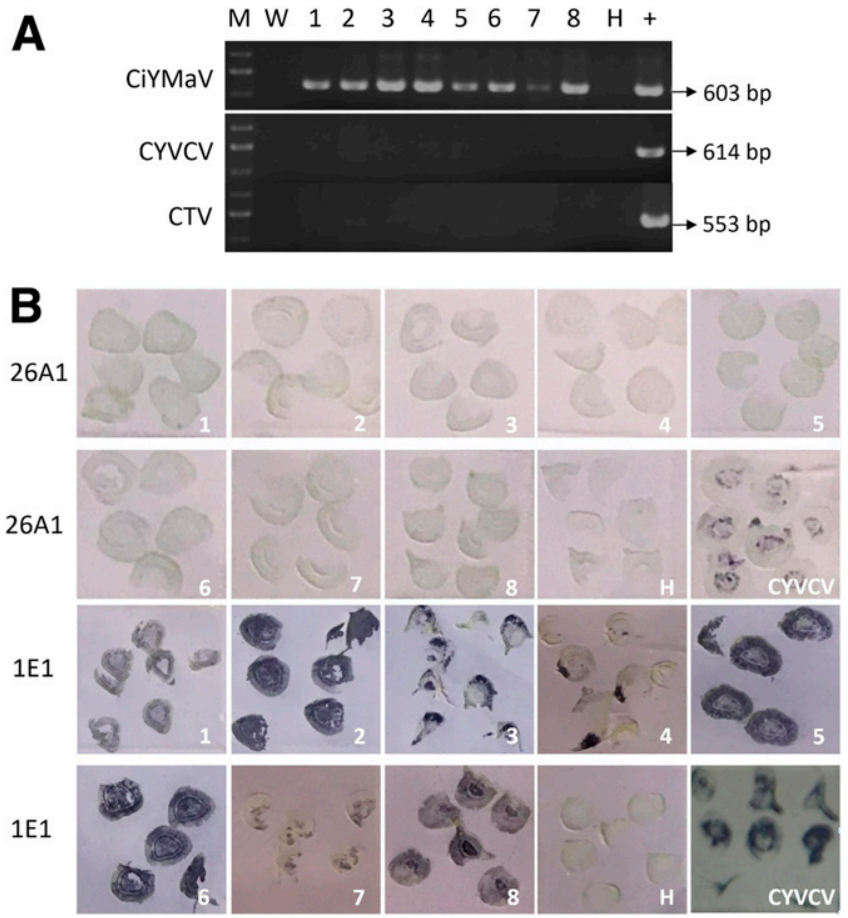

Fig. 3. Detection of citrus yellow mottle-associated virus (CiYMaV), inoculated on different citrus varieties, using reverse-transcription (RT)-PCR and direct tissue blot immunoassay (DTBIA) techniques. A, RT-PCR analysis of CiYMaV, citrus yellow vein clearing virus (CYVCV), and citrus tristeza virus (CTV) using specific primers (Supplementary Table S1). Lane M, DL2000 marker; lane W, water control; lanes 1 to 8, samples 1 to 8; lane $\mathrm{H}$, healthy control; and lane + , positive controls (PCV31 isolate in the case of CiYMaV; singly infected isolates from the Citrus Research Institute virus collection in the case of CTV and CYVCV). B, Serological detection of samples from different citrus varieties infected with CiYMaV or CYVCV by DTBIA using two monoclonal antibodies (1E1 and 26A1) specific for CYVCV. Samples 1 to 8 are infected by CiYMaV: 1 , Dweet tangor; 2 , Morocco sour orange; 3,6 , and 7 , Eureka lemon; 4, Daidai sour orange; 5, Chandler pummelo; 8, Symons sweet orange (SSO); H, noninfected control; and CYVCV, CYVCV-infected SSO, positive control. react with MAb 26A1, they showed cross-reactivity with the 1E1 antibody, with a variable signal intensity on the membrane likely generated by different virus titers in the tested samples (Fig. 3B). As expected, the control sample infected by CYVCV reacted against both MAbs, thus showing that CiYMaV and CYVCV can be serologically discriminated using MAb 26A1 (Fig. 3B).

Biological assays. To further investigate the biological features of CiYMaV, 10 citrus indicator plants (Cp, DT, DSO, EL, ML, MSO, $\mathrm{RL}$, SSO, TBO, and WNO) were graft inoculated with bark from the SSO PCV31 isolate, which was previously shown to be infected by $\mathrm{CiYMaV}$ and five viroids. In parallel experiments, three replicates of the same indicator species were grafted with bark tissues from virus-free SSO plants and used as negative controls. When assayed by RT-PCR using specific primers to detect $\mathrm{CiYMaV}$ and the five viroids identified in the PCV31 isolate, all of the indicators inoculated with the virus-free SSO tested negative. At $1 \mathrm{mpi}$, CiYMaV was
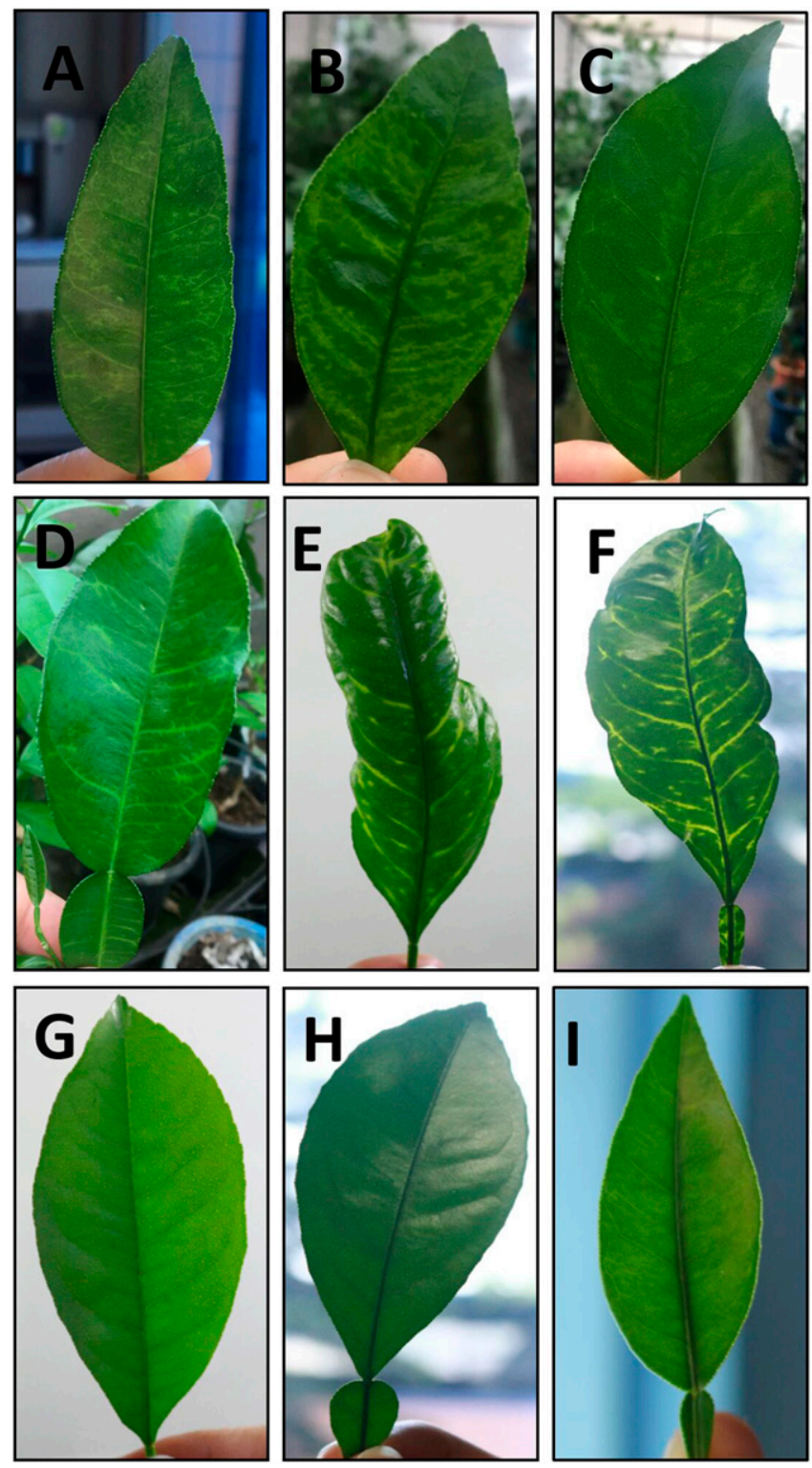

Fig. 4. Symptoms observed in different citrus varieties infected with citrus yellow mottle-associated virus (CiYMaV) or citrus yellow vein clearing virus (CYVCV). A and $\mathbf{B}$, Mottling on Dweet tangor infected by CiYMaV. C, Oak-leaf pattern on Washington navel orange infected by CiYMaV. D, Vein yellowing on Chandler pummelo infected by CiYMaV. $\mathbf{E}$ and $\mathbf{F}$, Vein clearing on Eureka lemon (EL) and Daidai sour orange (DSO), respectively, infected with CYVCV. G, No symptom on EL infected by CiYMaV. H, No symptom on DSO infected by CiYMaV. I, No symptom on Symons sweet orange infected by CYVCV. 
detected by RT-PCR in only a few plants graft inoculated with the PCV31 isolate. However, all indicators tested positive for CiYMaV at 3 and 5 mpi. Interestingly, different combinations of viroids or, in three cases, no viroids were detected in these plants, thus showing that the five viroids in the PCV31 tree were not always transferred by grafting (Supplementary Table S2). In the context of our study, these findings have a major relevance. In fact, inspections for symptom expression in the graft-inoculated plants, carried out during a period of 1 ypi, showed that only some of the PCV31 graft-inoculated species (SSO, DT, WNO, and Cp) developed leaf symptoms. More specifically, all of the graft-inoculated SSO showed symptoms of vein yellowing (Fig. 1A) and all DT indicators developed leaf mottling (Fig. 4A), with the latter symptom being more persistent and becoming more evident over time (more extended yellowing areas) (Fig. 4B). These plants tested positive to $\mathrm{CiYMaV}$ and to one or more or no viroids (Supplementary Table S2). The absence of viroids, observed in one DT graft-inoculated plant, was of particular relevance because it clearly showed that $\mathrm{CiYMaV}$ alone (in the absence of any viroid) was able to elicit the typical leaf symptoms. Regarding WNO and $\mathrm{Cp}$, three of four indicators showed symptoms of oak-leaf pattern and vein yellowing, respectively (Fig. 4C and D), with CiYMaV detected in all symptomatic plants. In both cases, one or more viroids coinfected the grafted indicator plants but no specific viroid or combination of viroids was closely associated with the observed leaf symptoms. Moreover, although infected by $\mathrm{CiYMaV}$ and several combinations of viroids (Supplementary Table S2), other indicator species (DSO, EL, ML, MSO, RL, and TBO) did not show any leaf symptoms after graft inoculation with the PCV31 isolate, thus indicating that the symptomatic responses observed in other species or varieties are host specific, with viroids playing no role in leaf symptom expression. Finally, no symptom was observed in the mechanically inoculated herbaceous hosts and CiYMaV was not detected in these inoculated plants by RT-PCR.

Parallel bioassays performed by graft inoculating CYVCV in DSO, EL, and SSO showed biological divergence between this virus and $\mathrm{CiYMaV}$. Although, in agreement with previous reports (Catara et al. 1993), CYVCV induced vein clearing in DSO and EL (Fig. 4E and $\mathrm{F}$, respectively), CiYMaV was not associated with any leaf symptom in these hosts (Fig. 4G and H, respectively). Moreover, CiYMaV was associated with vein yellowing and mottling in SSO (Fig. 1), whereas CYVCV did not induce any leaf symptom in this host (Fig. 4I), as also reported previously (Bin et al. 2017). These data show that it is possible to discriminate $\mathrm{CiYMaV}$ and CYVCV by bioassays.

Virus particle morphology. Observations by TEM of negatively stained leaf extracts from the CiYMaV-infected symptomatic SSO sample showed filamentous virus-like particles 600 to $700 \mathrm{~nm}$ in length and 13 to $14 \mathrm{~nm}$ in diameter (Fig. 5), similar to those observed in other plants infected by other members of the family Alphaflexiviridae (Adams et al. 2011; Loconsole et al. 2012a). These particles were not found in the noninoculated SSO control samples or in the herbaceous hosts inoculated with sap from the PVC31 isolate that tested negative also to $\mathrm{CiYMaV}$-specific RT-PCR assays, thus indicating a close association between the observed virus-like particles and $\mathrm{CiYMaV}$ infection.

New virus occurrence and sequence diversity. To accurately determine the presence of $\mathrm{CiYMaV}$ in the 120 symptomatic samples collected throughout the Punjab Province, Pakistan, specific RTPCR primers (JC-CiYMaV-F/R) (Supplementary Table S1) were designed to amplify part of the $\mathrm{CP}$ gene of the virus. The 603-bp expected amplicon was consistently amplified in 74 samples (about $62 \%$ of the tested samples) (Table 1), including the six SSO isolates PCV31, PCV49, PCV59, PCV62, PCV64, and PCV82 that developed leaf symptoms and were shown to be CYVCV-free at the beginning of this study (see above). Interestingly, in the collection of samples from Pakistan, CiYMaV was mainly found in mixed infections with CYVCV (45\%) or CTV (9.2\%). The same detection method was used for carrying out a preliminary survey on the possible presence of $\mathrm{CiYMaV}$ in Yunnan Province, China, the Chinese province in which CYVCV was detected for the first time (Chen et al. 2014). Leaf samples from 200 citrus trees grown in this province were collected randomly and tested. CiYMaV was not detected in any of the samples from Yunnan Province (data not shown), thus supporting the absence of this virus from this citrus-growing area where CYVCV is widely distributed.

Finally, taking advantage of the availability of the high number of $\mathrm{CiYMaV}$ isolates from Pakistan, a preliminary study on the sequence variability of this virus was carried out focusing on its CP. Specific primers were designed to amplify the whole-CP genomic fragment (987 bp) (Supplementary Table S1) by RT-PCR that was cloned and sequenced. The nucleotide sequence of the entire $\mathrm{CP}$ from 58 different $\mathrm{CiYMaV}$ isolates was determined and aligned to the corresponding fragment of the $\mathrm{CiYMaV}$ reference sequence (MK957246), thus showing nucleotide and amino acid sequence identities ranging between 95.91 and $100 \%$ and 94.48 and $100 \%$, respectively (data not shown).

\section{Discussion}

An initial systematic survey by RT-PCR of widely distributed citrus viruses showed that CTV, CYVCV, and citrus viroids but not CCGaV, CiVA, CLBV, CPsV, CTLV, and SDV were present in the field isolates from Punjab Province, Pakistan. CTV and CYVCV
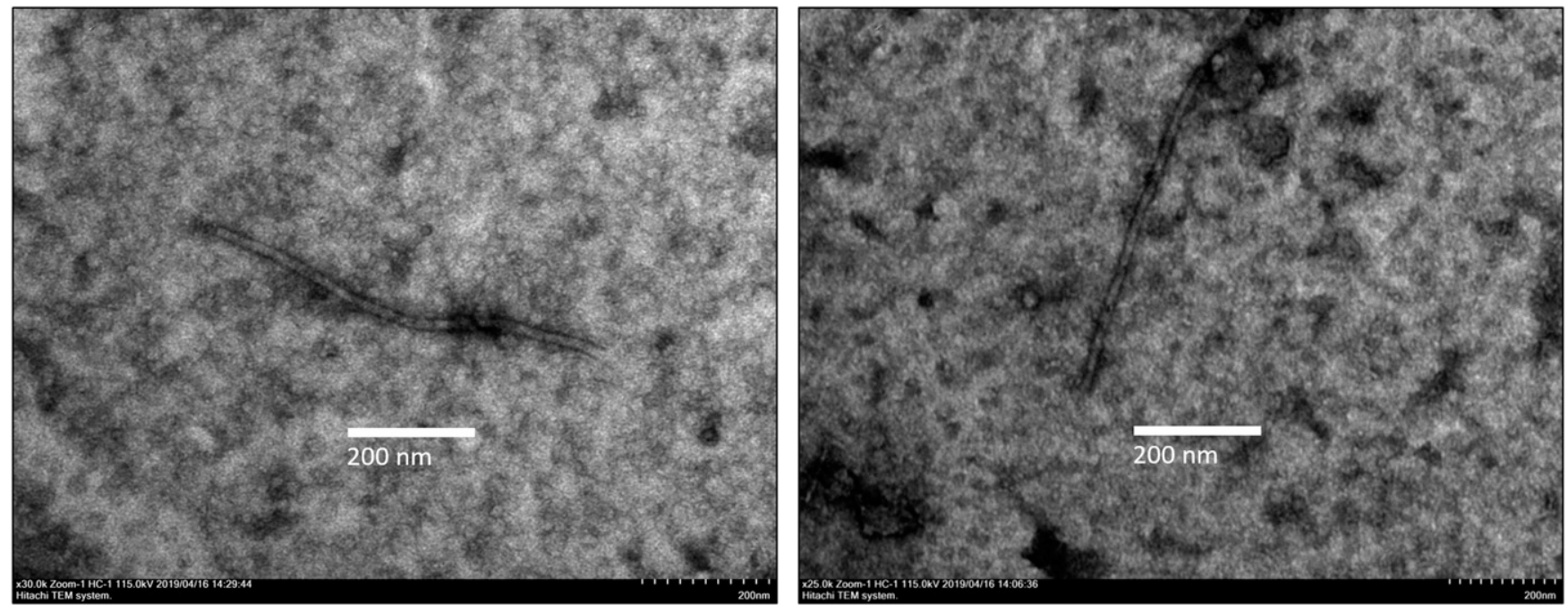

Fig. 5. Transmission electron microscopy observations (after negative staining) of the extracts from fresh leaves of symptomatic citrus yellow mottle-associated virus-infected Symons sweet orange trees. The filamentous and flexuous viral-like particles are 600 to $700 \mathrm{~nm}$ long and 10 to $20 \mathrm{~nm}$ wide. 
were mainly found in mixed infections, thus providing results similar to those reported by others in the same region (Catara et al. 1993; Iftikhar et al. 2009). In addition, further investigation of isolates inducing virus-like symptoms on the leaves of SSO indicator plants but that did not test positive to any of the assayed viruses or to ' $\mathrm{Ca}$. L. asiaticus' allowed the identification of a novel positive-sense ssRNA virus $\mathrm{CiYMaV}$.

From molecular and phylogenetic perspectives, CiYMaV resembles ICRSV and CYVCV, the two current members of the genus Mandarivirus (Fig. 2). The elongated and flexuous virus-like particles observed by TEM in CiYMaV-infected samples are also consistent with the size and the shape of mandariviruses (Fig. 5) (Loconsole et al. 2012a; Rustici et al. 2000). Species demarcation criteria have not been defined yet for the members of this genus. However, the International Committee on Taxonomy of Viruses has proposed nucleotide or amino acid sequence identity of whole CP or REP lower than about 72 or $80 \%$, respectively, as the identity values to be considered to assign viruses to different species in the genera under the family Alphaflexiviridae (Adams et al. 2011). Identity values of CiYMaV $\mathrm{REP}$ and $\mathrm{CP}$ with CYVCV, the closest related mandarivirus, are below or very close to these limits (Table 2). Moreover, the observed cross-reactivity of a CYVCV-specific antibody (MAb 1E1) with $\mathrm{CiYMaV}$ and the absence of any reactivity of $\mathrm{CiYMaV}$ with another CYVCV-specific MAb (MAb 26A1) showed that CiYMaV can be clearly distinguished from CYVCV based on serological features (Fig. 3B). The divergence between CiYMaV and CYVCV was also shown at the biological level, due to clearly different symptoms induced in EL, DSO, and SSO by the two viruses. Because CYVCV and ICRSV are both mechanically transmissible to herbaceous hosts, additional attempts using different inoculation buffers and isolates are needed for a conclusive statement on mechanical transmissibility of $\mathrm{CiYMaV}$ to herbaceous hosts. Altogether, molecular, phylogenetic, serological, and biological data reported here are consistent with the proposal to include $\mathrm{CiYMaV}$ as a novel species in the genus Mandarivirus.

Regarding the association of CiYMaV with leaf symptoms in some Citrus spp., the bioassays were performed by graft inoculating four replicates of 10 different Citrus spp. or varieties with bark patches from the isolate PCV31, which was coinfected by CiYMaV and five viroids. A careful analysis of virus and viroid transmission in the inoculated indicators allowed us to exclude the association of one viroid, or a combination of viroids, with the leaf symptoms observed in the inoculated Citrus spp. SSO (Fig. 1), DT (Fig. 4A and B), WNO (Fig. 4C), and Cp (Fig. 4D), thus strongly supporting the conclusion that viroids were not implicated in the elicitation of symptoms in the leaves. Accordingly, vein banding, mottling, flecking, and oak leaf pattern symptoms in citrus were never associated with viroid infections, or in single mixed infections with viruses (Duran-Vila 2019). This evidence was even more solid in the graft-inoculated and CiYMaV-infected DT plant that developed leaf mottling in the absence of any viroid, thus strongly supporting the pathogenic role of CiYMaV. Because this DT indicator was only infected by CiY$\mathrm{MaV}$, it could become the source material for bioassays to further investigate the pathogenic features of this novel virus in other Citrus spp.

The frequent mixed infections of CiYMaV and CYVCV observed in the isolates from the Punjab Province of Pakistan, and the $\mathrm{CiYMaV}$-associated leaf symptoms resembling those induced by CYVCV, open the question of whether CiYMaV is also present but unnoticed in neighboring countries such as China and India. In this respect, the preliminary RT-PCR-based survey performed in Yunnan Province, the first Chinese territory where CYVCV was found (Chen et al. 2014), showed that CiYMaV was not present or widely distributed in this area. Therefore, the RT-PCR detection methods developed in this study could be of immediate use to further extend similar surveys in other regions in which citrus is grown.

In contrast to CiYMaV, CYVCV is already widespread in China and in other citrus-growing areas, where it causes serious losses in the citrus industry (Chen et al. 2014) and has the potential to become a serious emerging disease worldwide. The fact that this virus is transmitted by whiteflies (Zhang et al. 2019) and aphids (Zhang et al. 2018) increases this risk. Whether the closely related CiYMaV is also transmitted by a vector remains unknown. However, the molecular, biological, serological, and morphological data on this virus, together with the detection methods reported and discussed in this study, provide the basic information to initiate studies on the impact and epidemiology of this novel mandarivirus and to develop appropriate measures to contain its further spread.

\section{Acknowledgments}

We thank L. Rubino for critical reading of the manuscript, and the editor and three anonymous reviewers for their constructive comments and suggestions.

\section{Literature Cited}

Adams, M. J., Antoniw, J. F., Bar-Joseph, M., Brunt, A. A., Candresse, T., Foster, G. D., and Fauquet, C. M. 2004. Virology Division News: The new plant virus family Flexiviridae and assessment of molecular criteria for species demarcation. Arch. Virol. 149:1045-1060.

Adams, M. J., Antoniw, J. F., and Kreuze, J. 2009. Virgaviridae: A new family of rod-shaped plant viruses. Arch. Virol. 154:1967-1972.

Adams, M. J., Candresse, T., Hammond, J., Kreuze, J. F., Martelli, G. P., Namba, S., Pearson, M. N., Ryu, K. H., and Vaira, A. M. 2011. Family Alphaflexiviridae. Pages 904-919 in: Virus Taxonomy. Ninth Report of the International Committee on Taxonomy of Viruses. Elsevier-Academic Press, Amsterdam, The Netherlands.

Atta, S., Zhou, C. Y., Zhou, Y., Cao, M. J., and Wang, X. F. 2012. Distribution and research advances of Citrus tristeza virus. J. Integr. Agric. 11:346-358.

Bernardo, P., Charlesdominique, T., Barakat, M., Ortet, P., Fernandez, E., Filloux, D., Hartnady, P., Rebelo, T. A., Cousins, S. R., Mesleard, F., Cohez, D., Yavercovski, N., Varsani, A., Harkins, G. W., Peterschmitt, M., Malmstrom, C. M., Martin, D. P., and Roumagnac, P. 2018. Geometagenomics illuminates the impact of agriculture on the distribution and prevalence of plant viruses at the ecosystem scale. ISME J. 12:173-184.

Bin, Y., Li, Z. A., Wu, J. X., Wang, X. F., Zhou, Y., Li, T. S., Yang, F. Y., Zhou, C. Y., and Song, Z. 2017. Development of an immunochromatographic strip test for rapid detection of citrus yellow vein clearing virus. Arch. Virol. 163: 349-357.

Bin, Y., Song, Z., Li, Z. A., and Zhou, C. Y. 2015. Direct tissue blot immunoassay for detection of Citrus yellow vein clearing virus. Acta Hortic. Sin. 42:1843-1850.

Bratlie, M. S., and Drabløs, F. 2005. Bioinformatic mapping of AlkB homology domains in viruses. BMC Genet. 6:1.

Byadgi, A. S., Ahlawat, Y. S., Chakraborty, N. K., Varma, A., Srivastava, M., and Milne, R. G. 1993. Characterisation of a filamentous virus associated with citrus ringspot in India. Indian Phytopathol. 51:225-232.

Cao, M. J., Atta, S., Liu, Y. Q., Wang, X. F., Zhou, C. Y., Mustafa, A., and Iftikhar, Y. 2009. First report of Citrus bent leaf viroid and Citrus dwarfing viroid from citrus in Punjab, Pakistan. Plant Dis. 93:840.

Cao, M. J., Atta, S., Su, H. N., Wang, X. F., Wu, Q., Li, Z. A., and Zhou, C. Y. 2013. Molecular characterization and phylogenetic analysis of Citrus viroid $V$ isolates from Pakistan. Eur. J. Plant Pathol. 135:11-21.

Cao, M. J., Li, P., Zhang, S., Yang, F., Zhou, Y., Wang, X., and Li, Z. 2018. Molecular characterization of a novel citrivirus from citrus using nextgeneration sequencing. Arch. Virol. 163:3479-3482.

Cao, M. J., Wu, Q., Atta, S., Su, H. N., Yu, Y. Q., Chen, H. M., and Zhou, C. Y. 2016. First molecular evidence of Citrus yellow vein clearing virus from citrus in Punjab, Pakistan. Plant Dis. 100:540.

Cao, M. J., Yu, Y. Q., Tian, X., Yang, F. Y., Li, R. H., and Zhou, C. Y. 2017. First report of Citrus leaf blotch virus in lemon in China. Plant Dis. 101:1561.

Cao, M. J., Zhang, S., Li, M., Liu, Y. J., Dong, P., Li, S. R., and Zhou, Y. C. 2019. Discovery of four novel viruses associated with flower yellowing disease of green Sichuan pepper (Zanthoxylum Armatum) by virome analysis. Viruses 11:696.

Catara, A., Azzaro, A., Davino, M., and Polizzi, G. 1993. Yellow vein clearing of lemon in Pakistan. Pages 364-367 in: Proc. 12th Conf. Int. Organ. Citrus Virol. P. Moreno, J. V. da Graca, and L. W. Timmer, eds. IOCV, Riverside, CA, U.S.A.

Chen, H. M., Li, Z. A., Wang, X. F., Zhou, Y., Tang, K. Z., Zhou, C. Y., Zhao, X. Y., and Yue, J. Q. 2014. First report of Citrus yellow vein clearing virus on lemon in Yunnan, China. Plant Dis. 98:1747.

Chen, H. M., Wang, X. F., Zhou, Y., Zhou, C. Y., Guo, J., and Li, Z. A. 2015. Biological characterization and RT-PCR detection of a new disease of Eureka lemon. Acta Phytophylac. Sin. 42:557-563.

Chou, Y. L., Hung, Y. J., Tseng, Y. H., Hsu, H. T., Yang, J. Y., Wang, C. H., and Chang, B. Y. 2013. The stable association of virion with the triple-geneblock protein 3-based complex of Bamboo mosaic virus. PLoS Pathog. 9: e1003405.

Duran-Vila, N. 2019. Viroids as companions of a professional career. Viruses 11: 245.

Ferron, F., Longhi, S., Henrissat, B., and Canard, B. 2002. Viral RNApolymerases-A predicted 2'-O-ribose methyltransferase domain shared by all Mononegavirales. Trends Biochem. Sci. 27:222-224. 
Gao, Y. L., Zhou, C. Y., Wang, X. F., Zhou, Y., and Liu, Y. 2006. RT-PCR detection of Satsuma dwarf virus. Acta Phytophylac. Sin. 33:136-140.

Ghorbel, R., Navarro, L., and Duran-Vila, N. 1998. Biological characterization of citrus tristeza virus isolates by in vitro tissue cultures. Plant Pathol. 47:333-340.

Grimaldi, V., and Catara, A. 1996. Association of a filamentous virus with yellow vein clearing of lemon. Pages 343-345 in: Proc. 13th Conf. Int. Organ. Citrus Virol. IOCV, Riverside, CA, U.S.A.

Hadidi, A., Flores, R., Candresse, T., and Barba, M. 2016. Next-generation sequencing and genome editing in plant virology. Front. Microbiol. 7:1325.

Iftikhar, Y., Khan, M. A., Rashid, A., Mughal, S. M., Iqbal, Z., Batool, A., Abbas, M., Khan, M. M., Muhammand, S., and Jaskani, M. J. 2009. Occurrence and distribution of citrus tristeza closterovirus in the Punjab and NWFP, Pakistan. Pak. J. Bot. 41:373-380.

Jagoueix, S., Bové, J. M., and Garnier, M. 1996. PCR detection of the two 'Candidatus' liberobacter species associated with greening disease of citrus. Mol. Cell. Probes 10:43-50.

Jelkmann, W. 1994. Nucleotide sequences of apple stem pitting virus and of the coat protein gene of a similar virus from pear associated with vein yellows disease and their relationship with potex- and carlaviruses. J. Gen. Virol. 75: 1535-1542.

Koonin, E. V. 1991. The phylogeny of RNA-dependent RNA polymerases of positive-strand RNA viruses. J. Gen. Virol. 72:2197-2206.

Liu, Z., Sunzhu, Y. J., Zhou, X. P., Hong, J., and Wu, J. X. 2016. Monoclonal antibody-based serological detection of Citrus yellow vein clearing virus in citrus groves. J. Integr. Agric. 15:60345-60347.

Loconsole, G., Önelge, N., Potere, O., Giampetruzzi, A., Bozan, O., Satar, S., De Stradis, A., Savino, V., Yokomi, R. K., and Saponari, M. 2012a. Identification and characterization of Citrus yellow vein clearing virus, a putative new member of the genus Mandarivirus. Phytopathology 102:1168-1175.

Loconsole, G., Saldarelli, P., Doddapaneni, H., Savino, V., Martelli, G. P., and Saponari, M. 2012b. Identification of a single-stranded DNA virus associated with citrus chlorotic dwarf disease, a new member in the family Geminiviridae. Virology 432:162-172.

Lv, C. J., Zhou, C. Y., Zhou, Y., and Tang, K. Z. 2007. Detection of Citrus psorosis virus by one-step RT-PCR and its annual distribution in different parts of Dweet tangor. Plant Prot. 33:42-45.

Maliogka, V., Minafra, A., Saldarelli, P., Ruiz-García, A., Glasa, M., Katis, N., and Olmos, A. 2018. Recent advances on detection and characterization of fruit tree viruses using high-throughput sequencing technologies. Viruses 10:436.

Morozov, S. Y., and Solovyev, A. G. 2003. Triple gene block: Modular design of a multifunctional machine for plant virus movement. J. Gen. Virol. 84: 1351-1366.

Mushegian, A. R., and Koonin, E. V. 1993. Cell-to-cell movement of plant viruses. Arch. Virol. 133:239-257.

Navarro, B., Minutolo, M., De Stradis, A., Palmisano, F., Alioto, D., and Di Serio, F. 2018a. The first phlebo-like virus infecting plants: A case study on the adaptation of negative-stranded RNA viruses to new hosts. Mol. Plant Pathol. 19:1075-1089.

Navarro, B., Zicca, S., Minutolo, M., Saponari, M., Alioto, D., and Di Serio, F. 2018b. A negative-stranded RNA virus infecting citrus trees: The second member of a new genus within the order Bunyavirales. Front. Microbiol. 9: 2340 .

Önelge, N., Satar, S., Elibüyük, Ö., Bozan, O., and Kamberoğlu, M. 2011. Transmission studies on Citrus yellow vein clearing virus. Pages 11-14 in: Proc. 18th Conf. Int. Organ. Citrus Virol. J. V. da Graca, R. F. Lee, and R. K. Yokomi, eds. IOCV, Riverside, CA, U.S.A

Prabha, K., and Baranwal, V. K. 2012. The genome sequence of an isolate of Indian citrus ringspot virus infecting the sweet orange in India. J. Virol. 86: 12446-12447.

Rupasov, V. V., Morozov, S. Y., Kanyuka, K. V., and Zavriev, S. K. 1989. Partial nucleotide sequence of potato virus M RNA shows similarities to potexviruses in gene arrangement and the encoded amino acid sequences. J. Gen. Virol. 70: 1861-1869.
Rustici, G., Accotto, G. P., Noris, E., Masenga, V., Luisoni, E., and Milne, R. G. 2000. Indian citrus ringspot virus: A proposed new species with some affinities to potex-, carla-, fovea-and allexiviruses. Arch. Virol. 145:1895-1908.

Skryabin, K. G., Morozov, S. Y., Kraev, A. S., Rozanov, M. N., Chernov, B. K., Lukasheva, L. I., and Atabekov, J. G. 1988. Conserved and variable elements in RNA genomes of potexviruses. FEBS Lett. 240:33-40.

Song, Z., Zhou, C. Y., Liu, K. H., and Li, Z. A. 2011. Establishment of nested RT PCR for detecting Citrus tatter leaf virus. J. Fruit Sci. 28:458-462.

Tan, F.-C., and Swain, S. M. 2007. Functional characterization of AP3, SOC1 and WUS homologues from citrus (Citrus sinensis). Physiol. Plant. 131:481-495.

Ur Rehman, A., Li, Z. Y., Yang, Z. K., Waqas, M., Wang, G. P., Xu, W. X., Li, F., and Hong, N. 2019. The coat protein of citrus yellow vein clearing virus interacts with viral movement proteins and serves as an RNA silencing suppressor. Viruses 11:329.

Vives, M. C., Velázquez, K., Pina, J. A., Moreno, P., Guerri, J., and Navarro, L. 2013. Identification of a new enamovirus associated with citrus vein enation disease by deep sequencing of small RNAs. Phytopathology 103:1077-1086.

Wu, G. A., Prochnik, S., Jenkins, J., Salse, J., Hellsten, U., Murat, F., Perrier, X. Ruiz, M., Scalabrin, S., Terol, J., Takita, M. A., Labadie, K., Poulain, J., Couloux, A., Jabbari, K., Cattonaro, F., Del Fabbro, C., Pinosio, S., Zuccolo, A., Chapman, J., Grimwood, J., Tadeo, F. R., Estornell, L. H., Muñoz-Sanz, J. V., Ibanez, V., Herrero-Ortega, A., Aleza, P., Pérez-Pérez, J., Ramón, D., Brunel, D., Luro, F., Chen, C. X., Farmerie, W. G., Desany, B., Kodira, C., Mohiuddin, M., Harkins, T., Fredrikson, K., Burns, P., Lomsadze, A., Borodovsky, M., Reforgiato, G., Freitas-Astúa, J., Quetier, F., Navarro, L., Roose, M., Wincker, P., Schmutz, J., Morgante, M., Machado, M. A., Talon, M., Jaillon, O., Ollitrault, P., Gmitter, F., and Rokhsar, D. 2014. Sequencing of diverse mandarin, pummelo and orange genomes reveals complex history of admixture during citrus domestication. Nat. Biotechnol. 32:656-662.

Xu, Q., Chen, L. L., Ruan, X. A., Chen, D. J., Zhu, A. D., Chen, C. L., Bertrand, D., Jiao, W. B., Hao, B. H., Lyon, M. P., Chen, J. J., Gao, S., Xing, F., Lan, H., Chang, J. W., Ge, X. H., Lei, Y., Hu, Q., Miao, Y., Wang, L., Xiao, S. X., Biswas, M. K., Zeng, W. F., Guo, F., Cao, H. B., Yang, X. M., Xu, X. W. Cheng, Y. J., Xu, J., Liu, J. H., Luo, O. J., Tang, Z. H., Guo, W. W., Kuang, H. H., Zhang, H. Y., Roose, M. L., Nagarajan, N., Deng, X. X., and Ruan, Y. J. 2013. The draft genome of sweet orange (Citrus sinensis). Nat. Genet. 45:59-66

Yokomi, R. K., Selvaraj, V., Maheshwari, Y., Saponari, M., Giampetruzzi, A., Chiumenti, M., and Hajeri, S. 2017. Identification and characterization of Citrus tristeza virus isolates breaking resistance in trifoliate orange in California. Phytopathology 107:901-908.

Yu, Y. Q., Wu, Q., Su, H. N., Wang, X. F., Cao, M. J., and Zhou, C. Y. 2017. Smal RNA deep sequencing reveals full-length genome of Citrus yellow vein clearing virus in Chongqing, China. J. Integr. Agric. 16:503-508.

Zhang, Y. H., Liu, C. H., Wang, Q., Wang, Y. L., Zhou, C. Y., and Zhou, Y. 2019 Identification of Dialeurodes citri as a Vector of Citrus yellow vein clearing virus in China. Plant Dis. 103:65-68.

Zhang, Y. H., Wang, Y. L., Qin, W., Cao, M. J., Zhou, C. Y., and Yan, Z. 2018 Identification of Aphis spiraecola as a vector of Citrus yellow vein clearing virus. Eur. J. Plant Pathol. 152:841-844.

Zhang, Y. P., Kirkpatrick, B. C., Smart, C. D., and Uyemoto, J. K. 1998. cDNA cloning and molecular characterisation of cherry green ring mottle virus. J. Gen. Virol. 79:2275-2281.

Zhou, Y., Chen, H. M., Cao, M. J., Wang, X. F., Jin, X., Liu, K. H., and Zhou, C. Y. 2017. Occurrence, distribution, and molecular characterization of Citrus yellow vein clearing virus in China. Plant Dis. 101:137-143.

Zhou, Y., Wang, X. F., Tang, K. Z., and Zhou, C. Y. 2004. Study on CP/Hinf I RFLP groups of citrus tristeza virus in Chongqing. J. Southwest Univ. 26: 420-422.

Zhou, Z. Y., Da Graca, J. V., Freitas-Astúa, J., Vidalakis, G., Duran-Vila, N., and Lavag, I. 2020. Citrus viruses and viroids. Pages 391-410 in: The Genus Citrus. M. Talon, M. Caruso, and F. G. Gmitter, Jr., eds. Elsevier Science, Duxford, UK. 